\title{
Polymerization of Sulfur-Containing Aldehydes. IV. Mechanism of Polymerization with Organoaluminum
}

\author{
Noboru Yamamoto and Iwao Yamashita \\ Government Industrial Research Institute, Osaka, \\ Midorigaoka 1, Ikeda, Osaka, Japan.
}

(Received May 29, 1974)

\begin{abstract}
The mechanism of the polymerization of sulfur-containing aldehydes initiated by $\mathrm{AlEt}_{3}$ or $\mathrm{AlEt}_{3}$-alcohol catalyst systems has been studied. The equimolar reaction of $\mathrm{AlEt}_{3}$ with the aldehyde under polymerization conditions formed $\mathrm{Et}_{2} \mathrm{AlOR}$. The polymerization using the monoalkoxides, which were prepared from $\mathrm{AlEt}_{3}$ and the alcohols obtained with the reduction of monomer, was essentially identical with those using $\mathrm{AlEt}_{3}$ itself as initiator at $-78^{\circ} \mathrm{C}$. In the polymerizations at higher temperatures, $-25--35^{\circ} \mathrm{C}$, a linear oligomer was produced together with a dimeric ester and the polymer. From IR, NMR, and, tracer analyses it was found that the oligomers have ester and alkoxy end groups. In the polymerization by $\mathrm{AlEt}_{3}-t$-butyl alcohol(C-14 labeled $\left.\mathrm{Bu}^{\mathrm{H}} \mathrm{OH}\right)$ systems, a radioactive polymer was obtained. These observations can be interpreted in terms of a coordinated anionic mechanism. The possibility of an alternative mechanism, a cationic one, has been examined.

KEY WORDS Sulfur-Containing Aldehyde / Triethylaluminum /

Tracer Method / Radioactive Catalyst / Polymerization Mechanism /

Oligomer /
\end{abstract}

As described in a previous paper, ${ }^{1}$ the polymerization of sulfur-containing aldehydes by organoaluminum generally produced amorphous or low crystalline polymers. These gave the same infrared spectrum and X-ray pattern as those obtained by the typical cationic catalysts. However, the by-product of the polymerization by the former catalyst is a dimeric ester, while the latter gives a cyclic trimer. The formation of an ester under the polymerization condition has not been observed in the polymerization of usual aldehydes, and this suggests some noncationic feature of the polymerization. For the acetaldehyde polymerization by triethylaluminum $\left(\mathrm{AlEt}_{3}\right)$ or $\mathrm{AlEt}_{3}$-alcohol systems Furukawa, et al., suggested a coordinate anionic mechanism, in which the formation of the polymer having alkoxy and ester end groups was presumed. ${ }^{2}$ However, because of the insolubility and the instability of the polymers of higher aldehydes, the end group of such polymers has been examined only infrequently. In the present study, the mechanism of the initiation, the propagation, and the chain transfer in the polymerization of sulfur-containing aldehydes has been clarified through obtaining information about the end groups of the oligomer and the polymer by IR and NMR analyses as well as by a tracer method, in which a radioactive initiator or radioactive terminator was successfully used. For examination of the polymer end by using a tracer method, $\beta$-ethylthiobutyraldehyde was selected as monomer because its polymer is completely soluble in THF and stable enough to acetylate at high temperatures for purification.

\section{EXPERIMENTAL}

\section{Materials}

Monomers and Solvents. Sulfur-containing aldehydes were obtained and purified as described in the preceding paper. ${ }^{3}$ The following monomers were used in this study: $\beta$-methylthiobutyraldehyde $\left(\mathrm{CH}_{3} \mathrm{SCH}\left(\mathrm{CH}_{3}\right) \mathrm{CH}_{2} \mathrm{CHO}, \mathrm{MTBA}\right)$, $\beta$-methylthiopropionaldehyde $\quad\left(\mathrm{CH}_{3} \mathrm{SCH}_{2} \mathrm{CH}_{2}\right.$ CHO, MTPA), $\beta$-ethylthiopropionaldehyde $\left(\mathrm{CH}_{3}-\right.$ $\mathrm{CH}_{2} \mathrm{SCH}_{2} \mathrm{CH}_{2} \mathrm{CHO}$, ETPA), and $\beta$-ethylthio- 
butyraldehyde $\left(\mathrm{CH}_{3} \mathrm{CH}_{2} \mathrm{SCH}\left(\mathrm{CH}_{3}\right) \mathrm{CH}_{2} \mathrm{CHO}\right.$, ETBA). Solvents were dried and rectified by ordinary methods. Monomer and toluene were dried over synthetic zeorite F-9 which was activated by heating at $150^{\circ} \mathrm{C} / 0.2 \mathrm{mmHg}$ for $5 \mathrm{hr}$ prior to use. The water content of monomer and toluene was determined by using a KarlFischer apparatus and ethylene glycol-pyridine as solvent. After the ETBA-toluene mixture was dried over synthetic zeolite $\mathrm{F}-9$ at $0^{\circ} \mathrm{C}$ for two weeks, the water content was found to be $0.03-0.05 \mathrm{mg} / \mathrm{ml}$.

Alcohols. $\quad \gamma$-Methylthiobutanol $\left(\mathrm{CH}_{3} \mathrm{SCH}\left(\mathrm{CH}_{3}\right)\right.$ $\mathrm{CH}_{2} \mathrm{CH}_{2} \mathrm{OH}, \mathrm{MB}$ ) was prepared by the reduction of MTBA with $\mathrm{LiAlH}_{4}$ and purified by distillation. bp $87.5^{\circ} \mathrm{C} / 10 \mathrm{mmHg} ; n_{\mathrm{D}}^{20}=1.4864 ;$ Anal. Calcd for $\mathrm{C}_{5} \mathrm{H}_{12} \mathrm{OS}$ : C, 49.95; $\mathrm{H}, 10.06 ; \mathrm{S}$, 26.67\%; Found: C, 49.88, H, 10.21; S, 26.85\%. IR: $3400 \mathrm{~cm}^{-1}\left(\nu_{\mathrm{OH}}\right), 1050 \mathrm{~cm}^{-1}\left(\nu_{\mathrm{C}-\mathrm{O}}\right) . \quad \mathrm{NMR}$ $\left(\mathrm{CCl}_{4}\right): \delta 1.29 \mathrm{ppm}$ (doublet $\mathrm{CH}_{3} \mathrm{CH}$ ), $\delta 1.58$ $1.68 \mathrm{ppm}\left(\mathrm{CH}\left(\mathrm{CH}_{3}\right) \mathrm{CH}_{2} \mathrm{CH}_{2}\right), \delta 2.06 \mathrm{ppm}$ (singlet $\left.\mathrm{CH}_{3} \mathrm{~S}\right), \quad \delta \quad 2.68-2.88 \mathrm{ppm} \quad(\mathrm{SCH}), \quad \delta \quad 3.42 \mathrm{ppm}$ (singlet $\mathrm{OH}$ ), $\delta 3.66$ (triplet $-\mathrm{CH}_{2} \mathrm{O}-$ ). $\alpha$ Ethyl- $\gamma$-methylthiobutanol $\quad\left(\mathrm{CH}_{3} \mathrm{SCH}\left(\mathrm{CH}_{3}\right) \mathrm{CH}_{2}-\right.$ $\left.\mathrm{CH}\left(\mathrm{C}_{2} \mathrm{H}_{5}\right) \mathrm{OH}, \mathrm{EMB}\right)$ was separated from the hydrolysis products of the reaction mixture of $\mathrm{AlEt}_{3}$ with MTBA. bp $102-103^{\circ} \mathrm{C} / 16 \mathrm{mmHg}$; Anal. Calcd for $\mathrm{C}_{7} \mathrm{H}_{16} \mathrm{OS}$ : C, 56.71; $\mathrm{H}, 10.88$; $\mathrm{S}, 21.62 \%$. Found: $\mathrm{C}, 56.43 ; \mathrm{H}, 11.25 ; \mathrm{S}$, $21.45 \%$. IR: $3400 \mathrm{~cm}^{-1}\left(\nu_{\mathrm{OH}}\right), 1115 \mathrm{~cm}^{-1}\left(\nu_{\mathrm{C}-\mathrm{O}}\right)$. NMR $\left(\mathrm{CCl}_{4}\right): \delta 0.95 \mathrm{ppm}$ (triplet $\left.\mathrm{CH}_{3} \mathrm{CH}_{2}\right), \delta$ $1.30 \mathrm{ppm}$ (doublet $\mathrm{CH}_{3} \mathrm{CH}$ ), $\delta$ 1.4-1.9 ppm $\left(\mathrm{SCHCH}{ }_{2} \mathrm{CHO}+\mathrm{CH}_{2} \overline{\mathrm{CH}}_{3}\right.$ ), $\delta \quad 2.05 \mathrm{ppm}$ (singlet $\mathrm{SCH}_{3}$ ), $\delta 2.5-3.1 \mathrm{ppm}(\mathrm{SCH}), \delta 3.6 \mathrm{ppm}$ (singlet $\mathrm{OH}), \delta 3.5-3.9 \mathrm{ppm}(\mathrm{CHOH})$.

$t$-Butyl alcohol and methanol were rectified in the presence of sodium alkoxide and stored under nitrogen atmosphere. Radioactive methanol (C-14 labeled, $\stackrel{*}{\mathrm{C}} \mathrm{H}_{3} \mathrm{OH}, 1 \mathrm{mCi}$ ) and $t$-butyl alcohol (C-14 labeled, $\mathrm{Bu}^{\mathrm{t}} \mathrm{OH}, 0.2 \mathrm{mCi}$ ) obtained commercially were diluted with the corresponding nonradioactive alcohols.

Catalyst. $\mathrm{AlEt}_{3}$ was rectified under nitrogen atmosphere. Catalyst systems containing diethyl aluminum monoalkoxide ( $\mathrm{Et}_{2} \mathrm{AlOR}$ ) were prepared by the equimolar reaction of $\mathrm{AlEt}_{3}$ with alcohols in toluene at room temperature.

\section{Polymerization Procedure}

The polymerization at $-78^{\circ} \mathrm{C}$, the separation, and the purification of the products were carried out according to the same procedure as that mentioned in a previous paper ${ }^{1}$ except for the tracer experiments. All polymerization experiments were carried out under dried nitrogen atmosphere. Bulk polymerizations at temperatures between $-25^{\circ} \mathrm{C}$ and $-35^{\circ} \mathrm{C}$ were carried out in the same manner in a SHARP TE 202 thermostat. Precision was $\pm 0.1^{\circ}$ at $-30^{\circ} \mathrm{C}$. The polymerization was stopped by the addition of petroleum ether (PE) containing a small portion of water. After standing for $24 \mathrm{hr}$ at room temperature, the products were progressively fractionated with PE, ethyl ether (EE), and tetrahydrofuran (THF). The PE-soluble part was treated with the method described in a previous paper $^{1}$, and then solvent and unchanged monomer were removed under reduced pressure. The dimeric ester was separated from the residue and purified by repeated distillation. The EE-soluble part, the oligomer, was purified by the reprecipitation with $\mathrm{PE}$ from EE solution. The THF-soluble part was the polymer, which was recovered by the addition of EE. Since the oligomers of MTBA and ETBA are soluble in $\mathrm{PE}$, elution chromatography using an alumina column was applied in order to separate the linear oligomer from the dimeric ester completely.

\section{Measurements}

The viscosity was measured by using an Ostwald viscometer in THF at $30^{\circ} \mathrm{C}$. The molecular weight of the oligomer was measured by a KNAUER vapour-pressure osmometer in benzene at $45^{\circ} \mathrm{C}$. The molecular weight of Poly-ETBA was measured by a KNAUER membrane osmometer in toluene at $60^{\circ} \mathrm{C}$. The following relation between the viscosity measured in THF at $30^{\circ} \mathrm{C}$ and the molecular weight was obtained:

$$
[\eta]=5.15 \times 10^{-5} M^{0.95} \quad\left(M_{n}, 5-50 \times 10^{4}\right)
$$

The degree of aggregation of catalysts was measured by the cryoscopic method in benzene. NMR spectra were recorded with a JNM-PS-100 spectrometer (JEOL) in carbon tetrachloride at room temperature. TLC analysis was carried 
out using an alumina plate as the stationary phase and EE-PE $(2: 1-4: 1)$ as the developing solvent. The spots were detected by exposure to iodine vapor.

\section{Tracer Experiments}

Polymerization and Separation. Radioactive catalyst systems were prepared by the reaction of $\mathrm{AlEt}_{3}$ with $\stackrel{*}{\mathrm{Bu}} \mathrm{OH}$ in toluene at room temperature for $48 \mathrm{hr}$. Quantitative formation of the corresponding aluminum alkoxide was reported. ${ }^{4}$ Polymerization was carried out at $-78^{\circ} \mathrm{C}$ in toluene by using a catalyst of $1-3$ mol\% to monomer for a definite time; thereafter the terminator was added at $-40^{\circ} \mathrm{C}$. The system was kept for $2 \mathrm{hr}$ at room temperature, and then the product was fractionated by the addition of a large amount of methanol containing $1 \%$ of water. The methanol-soluble part contains the unchanged monomer, the Tishchenko reaction product (TP, the dimeric ester and ester containing catalyst fragment (OR)), but no polymer. The crude polymer was dissolved in THF and reprecipitated once with water.

Purification of Polymer (Control experiments). In order to measure only the radioactivity combined chemically in the polymer end, the unchanged catalyst or $\mathrm{OAl}(\mathrm{OR})_{2}$ group of polymer end should be completely removed from the polymerizate. The polymer was purified by repeated reprecipitation with water from THF solution or by combination of the reprecipitation and the end-capping with acetic anhydridepyridine ${ }^{5}$ until an almost constant value of the radioactivity in the polymer was obtained. The acetylation was carried out for the stabilization of the polymer, under the assumption that it occurs at hydroxy or $-\mathrm{OAl}\left(\mathrm{OCH}_{3}\right)_{2}$ end groups and does not affect any alkoxy end groups containing initiator fragment. The effectiveness of this purification procedure was shown by control experiments, in which the same procedure was applied to a mixture of nonradioactive polymer and radioactive $\mathrm{Et}_{2} \mathrm{AlOB}^{t}$. Radioactive catalyst $\mathrm{Et}_{2} \mathrm{AlOB}^{t}$ was added to poly-ETBA solution in toluene at room temperature and the solution was kept for $24 \mathrm{hr}$ at $-78^{\circ} \mathrm{C}$, then the polymer was recovered by adding methanol. The radioactivity in the polymer recovered was remarkably decreased by each repeated reprecipitation and became zero after the fourth reprecitation. It was further found that the radioactive contaminates in the polymer can be removed by acetylation. Consequently, this repeated acetylation followed by reprecipitation was used as the standard method for polymer purification. In addition, to the polymerization system of nonradioactive catalysts the corresponding radioactive catalyst was added at $-40^{\circ} \mathrm{C}$, and then the system was treated by the above procedure. The radioactivity in the polymer again became zero after repeated reprecipitation. This further supports the effectiveness of the purification method.

On the other hand, in the tracer experiments using $\stackrel{*}{\mathrm{C}} \mathrm{H}_{3} \mathrm{OH}$ as terminator, it is necessary to remove completely any uncombined $\stackrel{*}{\mathrm{C}_{3}} \mathrm{H}_{3} \mathrm{OH}$, $\left(\stackrel{*}{\mathrm{CH}_{3} \mathrm{O}}\right)_{2} \mathrm{AlOBu}^{\mathrm{t}}$, or $\left.-\mathrm{OAl}\left(\mathrm{O}_{\mathrm{CH}}\right)_{3}\right)_{2}$ groups which may be combined in the polymer ends. In this case, the following control experiments were carried out.

The nonradioactive polymer stabilized by acetylation was dissolved into toluene, thereafter recovered by the addition of $\stackrel{*}{\mathrm{C}} \mathrm{H}_{3} \mathrm{OH}$, and purified by the above method. Further, the nonradioactive polymer was kept for $24 \mathrm{hr}$ at $-78^{\circ} \mathrm{C}$ in toluene with a catalytic amount of $\mathrm{Et}_{2} \mathrm{AlOBu}^{\mathrm{t}}$, thereafter treated with $\stackrel{*}{\mathrm{C}} \mathrm{H}_{3} \mathrm{OH}$, and purified again. These control experiments showed that it was difficult to remove completely all trace amounts of the radioactive contaminates mentioned above, even by the combination of acetylation and reprecipitation. The retained radioactive contaminates corresponded to $0.05-$ $0.1 \mathrm{~mol} \%$ of the catalyst added.

Purification of TP and Linear Oligomer. The PE solution containing TP was washed repeatedly with water until a constant value of the radioactivity was obtained. The linear oligomer of MTPA was repeatedly purified by the reprecipitation method.

Measurement of Radioactivity. A sample (0.025 g) was dissolved in $5 \mathrm{ml}$ of THF and mixed with $5 \mathrm{ml}$ of toluene scintillator (toluene $200 \mathrm{ml}$, 
2,5-diphenyloxazole $0.8 \mathrm{~g}, 2,2,-p$-phenylene-bis(5phenyloxazole) $0.02 \mathrm{~g}$ ); the radioactivity of the solution was counted by a liquid scinitillation spectrometer (HORIBA Model LS-500).

\section{RESULTS AND DISCUSSION}

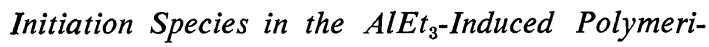
zation

It is generally known that $\mathrm{AlEt}_{3}$ adds to a carbonyl group of aldehyde by a Grignard-type reaction to give the corresponding aluminum monoalkoxide:

$$
\mathrm{RCHO}+\mathrm{AlEt}_{3} \longrightarrow \mathrm{Et}_{2} \mathrm{AlOCH}(\mathrm{Et}) \mathrm{R}
$$

In order to confirm whether such a reaction also occurs in the case of sulfur-containing aldehydes, the equimolar reaction of $\mathrm{AlEt}_{3}$ with MTBA under polymerization conditions has been examined by applying the method developed by Fujii, et al. ${ }^{6}$ When methanol was added to the equimolar mixture of MTBA and $\mathrm{AlEt}_{3}$ at $-78^{\circ} \mathrm{C}$, evolution of ethane gas was not observed, which indicated the absence of free $\mathrm{AlEt}_{3}$. EMB was recovered by the hydrolysis of the alkoxide, accompanied by a small amount of MB and the dimeric ester, and separated by distillation.

In addition, the reaction was examined at various temperatures from $-78^{\circ} \mathrm{C}$ to room temperature. In all cases, the amount of ethane evolved by the addition of methanol at room temperature of the reaction mixture corresponds to two ethyl groups in $\mathrm{Et}_{2} \mathrm{AlOR}$. This implies that further reaction of the $\mathrm{Et}_{2} \mathrm{AlOR}$ with MTBA to form $\operatorname{EtAl}(\mathrm{OR})_{2}$ does not occur. After hydrolysis of the reaction mixture, the products were separated by distillation. The yield ratio of EMB, MB, the dimeric ester, and unchanged MTBA were $62 \%, 17 \%, 15 \%$, and $5 \%$, respectively, in the reaction at $-40^{\circ} \mathrm{C}$ in toluene for $24 \mathrm{hr}$.

\section{Polymerization of $M T B A$ by $E t_{2}$ AlOR}

Results of the polymerization of MTBA in bulk or in toluene at $-78^{\circ} \mathrm{C}$ by $\mathrm{AlEt}_{3}$ and by the reaction products of $\mathrm{AlEt}_{3}$ with monomer aldehyde, MB, and EMB are given in Tabl I.

The polymer separated as the methanol-insoluble fraction was soluble in THF regardless of the kind of catalyst used and gave the identical IR spectrum. In all cases, the methanolsoluble fractions contain the dimeric ester, but no polymer. These facts seem to indicate that the polymerization by $\mathrm{AlEt}_{3}$ and by $\mathrm{Et}_{2} \mathrm{AlOR}$ proceeds by the same mechanism. The structure and solubility of the present polymer were not affected by the aging time of the catalyst system. This monoalkoxide is in monomeric form immediately after it is formed; however, it aggregates gradually to the dimeric form within $48 \mathrm{hr}$. As Table I shows the catalyst system used after aging for $48 \mathrm{hr}$ gave similar results to that of the polymerization by one without

Table I. Polymerization of MTBA by organoaluminum catalysts ${ }^{\mathrm{a}}$

\begin{tabular}{|c|c|c|c|c|c|c|}
\hline \multicolumn{3}{|c|}{ Catalyst } & \multirow{2}{*}{ Solvent } & \multicolumn{2}{|c|}{ Polymer } & \multirow{2}{*}{$\mathrm{TP}^{\mathrm{c}}, \underset{\%}{\text { Yield, }}$} \\
\hline & & Concn, $\mathrm{mol} \%$ & & Yield, $\%$ & {$[\eta]^{\mathrm{b}} \mathrm{d} l / \mathrm{g}$} & \\
\hline \multicolumn{2}{|l|}{$\mathrm{AlEt}_{3}$} & 3 & bulk & 40 & 5.8 & 11 \\
\hline \multicolumn{2}{|c|}{ " } & 3 & toluene & 88 & 9.6 & trace \\
\hline \multicolumn{2}{|c|}{$\mathrm{AlEt}_{3}-\mathrm{MTBA}(1: 1)$} & 2 & " & 55 & 3.5 & 4 \\
\hline " - EME & $(1: 1)^{\mathrm{e}}$ & 3 & bulk & 30 & 5.9 & 5 \\
\hline$" 1$ & $(1: 1)^{\mathrm{d}}$ & 3 & " & 28 & 5.7 & 7 \\
\hline$"-1 "$ & $(1: 1)^{\mathrm{d}}$ & 3 & toluene & 78 & 6.6 & 2 \\
\hline$"-\mathrm{MB}$ & $(1: 1)^{\mathrm{e}}$ & 1.5 & bulk & 33 & 4.7 & 8 \\
\hline$"-"$ & $(1: 1)^{\ominus}$ & 1.5 & toluene & 71 & 6.8 & 6 \\
\hline
\end{tabular}

a MTBA, $6 \mathrm{~g}$; toluene, $6 \mathrm{~g}$; temp, $-78^{\circ} \mathrm{C}$; time, $24 \mathrm{hr}$.

b $30^{\circ} \mathrm{C}$, in $\mathrm{THF}$.

c Tishchenko reaction products.

a Aging time, $48 \mathrm{hr}$.

e Used without aging. 


\section{N. Yамамото and I. Yamashita}

aging. This fact differs from the case of acetaldehyde polymerization, ${ }^{6}$ in which the ratio of the insoluble polymer to the total product polymer is increased with the increase of degree of aggregation of the resultant $\mathrm{Et}_{2} \mathrm{AlOR}$.

\section{Polymerization at Temperatures Close to the Ceiling Temperature}

In the polymerization at $-25^{\circ}--35^{\circ} \mathrm{C}$, the linear oligomer was formed, in all cases, together with TP and the polymer. The results of bulk polymerization of MTPA are given in Table II. In this case, TP, the oligomer, and the polymer were fractionated from the reaction mixture by solvents based on the difference of the solubility at room temperature. The PE-soluble part contains TP. $^{7-9}$ The dimeric ester, $\mathrm{CH}_{3} \mathrm{SCH}_{2} \mathrm{CH}_{2} \mathrm{COOCH}_{2} \mathrm{CH}_{2} \mathrm{CH}_{2} \mathrm{SCH}_{3}$, was isolated by fractional distillation. bp $107^{\circ} \mathrm{C} / 0.35$ mmHg; $n_{\mathrm{D}}^{20}=1.5075$. Anal. Calcd for $\mathrm{C}_{8} \mathrm{H}_{16} \mathrm{O}_{2} \mathrm{~S}_{2}$ : C, 46.12; H, 7.74; S, 30.78\%. Found: C, 46.25; $\mathrm{H}, 7.91 ; \mathrm{S}, 30.88 \%$. MW (VPO in benzene), 207 (calcd 208.3). Furthermore, the presence of $\mathrm{CH}_{3} \mathrm{SCH}_{2} \mathrm{CH}_{2} \mathrm{COOCH}(\mathrm{Et}) \mathrm{CH}_{2} \mathrm{CH}_{2} \mathrm{SCH}_{3}$ by $\mathrm{AlEt}_{3}$ catalyst, $\mathrm{CH}_{3} \mathrm{SCH}_{2} \mathrm{CH}_{2} \mathrm{COOBu}{ }^{\mathrm{t}}$ by $\mathrm{Et}_{2} \mathrm{AlOBu}^{\mathrm{t}}$ catalyst, and $\mathrm{CH}_{3} \mathrm{SCH}_{2} \mathrm{CH}_{2} \mathrm{COOPh}$ by $\mathrm{Et}_{2} \mathrm{AlOPh}$ catalyst was verified by $\mathrm{NMR}$ analysis of the residue or the fore-run of fractional distillation, although the complete separation of these from the dimeric ester was unsuccessful. Products in the polymerization at temperatures lower

Table II. Polymerization of MTPA with organoaluminum catalysts ${ }^{\mathrm{a}}$

\begin{tabular}{lcccrr}
\hline \multirow{2}{*}{ Catalyst } & $\begin{array}{c}\text { Temp, } \\
{ }^{\circ} \mathrm{C}\end{array}$ & \multicolumn{4}{c}{ Product, yield, $\%$} \\
\cline { 3 - 6 } & $\mathrm{I}^{\mathrm{b}}$ & $\mathrm{II}^{\mathrm{c}}(\mathrm{MW})^{\mathrm{d}}$ & $\mathrm{III}^{\ominus}$ & Total \\
\hline $\mathrm{AlEt}_{3}$ & -30 & 60 & 6 & 34 & 100 \\
$\prime \prime$ & -26 & 90 & $6(355)$ & 2 & 98 \\
$\mathrm{Et}_{2} \mathrm{AlOBu}$ & -30 & 41 & $5(570)$ & 54 & 100 \\
$\quad \prime \prime$ & -26 & 76 & $13(650)$ & 4 & 96 \\
$\mathrm{Et}_{2} \mathrm{AlOPh}$ & -30 & 50 & 17 & 19 & 86 \\
$\quad \prime \prime$ & -26 & 68 & $18(900)$ & 14 & 100 \\
\hline
\end{tabular}

a MTPA, $0.05 \mathrm{~mol}$; catalyst, $0.0005 \mathrm{~mol}$; time, 24 hr; bulk polymerization.

b I; Petroleum ether-soluble fraction, Tishchenko reaction products.

c II; ether-soluble fraction, oligomer.

d By VPO.

- III; THF-soluble fraction, polymer. than $-25^{\circ} \mathrm{C}$ were $\mathrm{TP}$, the oligomer, and the polymer. A colorless semisolid, which was separated as the EE-soluble part from the mixture, was found to be the oligomer by MW measurement. The oligomer in soluble in carbon tetrachloride, benzene, and toluene. The yield of TP increased upon raising the polymerization temperature. At a temperature above $-25^{\circ} \mathrm{C}$, TP formed in higher yield regardless of the structure of the catalyst used. The polymerizations by $\mathrm{Et}_{2} \mathrm{AlOBu}^{\mathrm{t}}$ or $\mathrm{Et}_{2} \mathrm{AlOPh}$ were similar to those by $\mathrm{AlEt}_{3}$. Results of the polymerization of ETPA, MTBA, and ETBA are shown in Table III. The linear oligomers of both MTBA and ETBA were partly soluble in PE; therefore, comlete separation of the oligomer by solvent from TP at room temperature was unsuccessful. The separation was accomplished by precipitating the oligometer from the $\mathrm{PE}$ solution at $-50^{\circ} \mathrm{C}$. Further complete separation was performed by elution chromatography using neutral alumina as the stationary phase, and PE and EE, successively, as eluent. The oligomer was collected from the fraction eluted with EE. The dimeric ester of ETPA, $\mathrm{C}_{2} \mathrm{H}_{5} \mathrm{SCH}_{2} \mathrm{CH}_{2}$ $\mathrm{COOCH}_{2} \mathrm{CH}_{2} \mathrm{CH}_{2} \mathrm{SC}_{2} \mathrm{H}_{5}$, was separated by distillation and characterized as follows: bp $123^{\circ} \mathrm{C} /$ $0.4 \mathrm{mmHg} ; n_{\mathrm{D}}^{20}=1.4999$. Anal. Calcd for $\mathrm{C}_{10} \mathrm{H}_{20^{-}}$ $\mathrm{O}_{2} \mathrm{~S}_{2}: \mathrm{C}, 50.81 ; \mathrm{H}, 8.52 ; \mathrm{S}, 27.13 \%$. Found: C, 50.74; $\mathrm{H}, 8.71 ; \mathrm{S}, 27.21 \%$. IR: $1737 \mathrm{~cm}^{-1}$ $\left(\nu_{\mathrm{C}=0}\right), 1220 \mathrm{~cm}^{-1}\left(\nu_{\mathrm{C}-0}\right), 1155 \mathrm{~cm}^{-1}\left(\nu_{\mathrm{C}-0}\right) . \quad$ NMR: $\delta 1.28 \mathrm{ppm}$ (triplet $\mathrm{CH}_{3} \mathrm{CH}_{2}$ ) $\delta \quad 1.65-2.11 \mathrm{ppm}$ (multiplet $-\mathrm{CH}_{2} \mathrm{CH}_{2} \mathrm{CH}_{2}, \quad \delta \quad 2.42-2.85 \mathrm{ppm}$ (complex $\mathrm{CH}_{2} \mathrm{C}=\mathrm{O}+\mathrm{SCH}_{2}$ ), $\delta \quad 4.19 \mathrm{ppm}$ (triplet $\left.\mathrm{OCH}_{2}\right)$. The dimeric ester of MTBA, $\mathrm{CH}_{3}$ $\mathrm{SCH}\left(\mathrm{CH}_{3}\right) \mathrm{CH}_{2} \mathrm{COOCH}_{2} \mathrm{CH}_{2} \mathrm{CH}\left(\mathrm{CH}_{3}\right) \mathrm{SCH}_{3}$ was also separated by distillation: bp $110^{\circ} \mathrm{C} / 0.3$ mmHg; $n_{\mathrm{D}}^{20}=1.4991$. Anal. Calcd for $\mathrm{C}_{10} \mathrm{H}_{20} \mathrm{O}_{2} \mathrm{~S}_{2}$ : C, 50.81; H, 8.52; S, 27.13\%. Found: C, 50.67; $\mathrm{H}, 8.65$; S, 27.33\%. IR: $1740 \mathrm{~cm}^{-1}\left(\nu_{\mathrm{C}=0}\right), 1235$ $\mathrm{cm}^{-1}\left(\nu_{\mathrm{C}-0}\right), 1165 \mathrm{~cm}^{-1}\left(\nu_{\mathrm{C}-0}\right)$. NMR: $1.31 \mathrm{ppm}$ (doublet $\left.\mathrm{CH}_{3} \mathrm{CH}\right), \delta \quad 1.68-1.90 \mathrm{ppm}\left(-\mathrm{OCH}_{2}\right.$ $\mathrm{CH}_{2} \mathrm{CH}-$ ), $\delta \quad 2.04 \mathrm{ppm}$ and $2.08 \mathrm{ppm}$ (two singlets $\mathrm{CH}_{3} \mathrm{~S}$ ), $\delta \quad 2.20-2.55 \mathrm{ppm}$ (complex $\mathrm{CH}_{2} \mathrm{C}=\mathrm{O}, \delta 2.56-2.83 \mathrm{ppm}$ and $2.90-3.18 \mathrm{ppm}$ (multiplet $\left.\mathrm{SCH}\left(\mathrm{CH}_{3}\right) \mathrm{CH}_{2}\right), \delta \quad 4.22 \mathrm{ppm}$ (triplet $\mathrm{OCH}_{2}$ ).

Structure of the Linear Oligomer of MTPA

The linear oligomer obtained in the polymeri- 
Mechanism of Aldehyde Polymerization with Organoaluminum

Table III. Polymerization of ETPA, MTBA, and ETBA by organoaluminums ${ }^{a}$

\begin{tabular}{|c|c|c|c|c|c|c|}
\hline \multirow{2}{*}{ Monomer } & \multirow{2}{*}{ Catalyst } & \multirow{2}{*}{ Temp, $\mathrm{C}^{\circ}$} & \multicolumn{4}{|c|}{ Fraction $^{\mathrm{b}}$, Yield, $\%$} \\
\hline & & & $\mathrm{I}(\mathrm{MW})^{\mathrm{c}}$ & $\mathrm{II}(\mathrm{MW})^{\mathrm{c}}$ & III & Total \\
\hline ETPA & $\mathrm{AlEt}_{3}$ & -35 & $53(330)$ & $4(2670)$ & 26 & 93 \\
\hline "I & " & -30 & 81 & 10 & 6 & 97 \\
\hline " & " & -27 & 80 & trace & 0 & 81 \\
\hline " & $\mathrm{Et}_{2} \mathrm{AlOBu}^{\mathrm{t}}$ & -35 & 34 & $5(1470)$ & 41 & 80 \\
\hline "I & " & -30 & 73 & $11(650)$ & 9 & 93 \\
\hline$" 1$ & " & -25 & $97^{d}$ & 0 & 0 & 97 \\
\hline MTBA & $\mathrm{AlEt}_{3}$ & -35 & 57 & 8 & 30 & 95 \\
\hline "I & "I & -32 & 87 & 7 & 6 & 100 \\
\hline$" \prime$ & $" \prime$ & -30 & 96 & 2 & 0 & 98 \\
\hline " & "I & -25 & $95^{\mathrm{d}}$ & 0 & 0 & 95 \\
\hline 11 & $\mathrm{Et}_{2} \mathrm{AlOPh}$ & -33 & 90 & 2 & 6 & 98 \\
\hline ETBA & $\mathrm{AlEt}_{3}$ & -35 & 51 & $17(5700)$ & 13 & 81 \\
\hline "I & " & -30 & 98 & 2 & 0 & 100 \\
\hline$" \prime$ & " & -25 & $98^{\mathrm{d}}$ & 0 & 0 & 98 \\
\hline "I & $\mathrm{Et}_{2} \mathrm{AlOBu}^{\mathrm{t}}$ & -35 & 55 & $13(10000)$ & 5 & 73 \\
\hline " & "I & -30 & 89 & 3 & 0 & 92 \\
\hline
\end{tabular}

a Monomer, $0.05 \mathrm{~mol}$; catalyst, $0.0005 \mathrm{~mol}$; time, $24 \mathrm{hr}$; bulk polymerization.

b I; petroleum ether-soluble fraction, Tishchenko reaction product +oligomer.

II; ether-soluble fraction, oligomer.

III; THF-soluble fraction, polymer.

c By VPO in benzene.

d No oligomer.

zation by $\mathrm{Et}_{2} \mathrm{AlOBu}^{\mathrm{t}}$ of MTPA was collected and further fractionated with EE-PE $(1: 4)$ mixture into a soluble part and an insoluble one. On the TLC of the formir, five spots were found in addition to the spot corresponding to the dimeric ester. Therefore, it may be assumed that these spots correspond to the linear oligomers. The insoluble part in EE-PE $(1: 4)$ mixture was again separated with EE-PE $(1: 2)$ to a soluble part and an insoluble one. The soluble part gave seven spots on the TLC but no spot corresponding to the dimeric ester. The IR spectrum and the NMR spectrum of the oligomer, together with those of the dimeric ester, are given in Figures 1 and 2. The IR spectra of the oligomer and the polymer are similar and show five strong bands at $1130-930 \mathrm{~cm}^{-1}$, which are assigned to the open chain $-\mathrm{O}-\mathrm{C}-\mathrm{O}-$ stretching. In the spectrum of the oligomer, $2920 \mathrm{~cm}^{-1}$ and $1430^{-1}$ bands due to the $\mathrm{CH}$ bond are more intense in comparison with those of the polymer. The absorption detected at 1740 $\mathrm{cm}^{-1}$ in the spectrum of the oligomer is at- tributed to the terminal ester group which might be formed by a chain-transfer reaction. This band became weaker as the degree of polymerization of the sample increased. An alternative possible mechanism, the cationic one, may be ruled out, since there is no sign of the characteristic hydroxy absorption near $3500 \mathrm{~cm}^{-1}$.

Thus, it was assumed that the main structure of the oligomer of MTPA can be represented as:

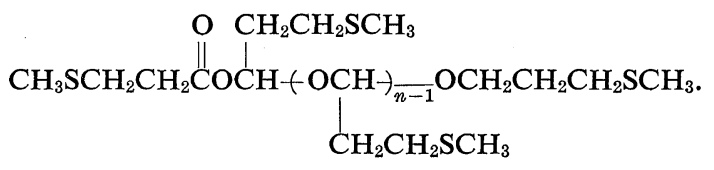

Peaks a and $b$, which appear in the NMR spectra of both the oligomer and the dimeric ester, can be assigned to the protons of $-\mathrm{OCH}_{2} \mathrm{CH}_{2}$ $\mathrm{CH}_{2} \mathrm{SCH}_{3}+-\mathrm{OCHCH}_{2} \mathrm{CH}_{2} \mathrm{SCH}_{3}$ and $\mathrm{CH}_{3} \mathrm{~S}$-, respectively. The broad peaks at $2.4-2.8 \mathrm{ppm}$ (peaks $c+c^{\prime}$ ) in the spectrum of the linear oligomer can be assigned to overlapping of $-\mathrm{SCH}_{2} \mathrm{CH}_{2} \stackrel{\mid}{\mathrm{C}}=\mathrm{O}$ and $-\mathrm{SCH}_{2} \mathrm{CH}_{2}-$ groups. The 


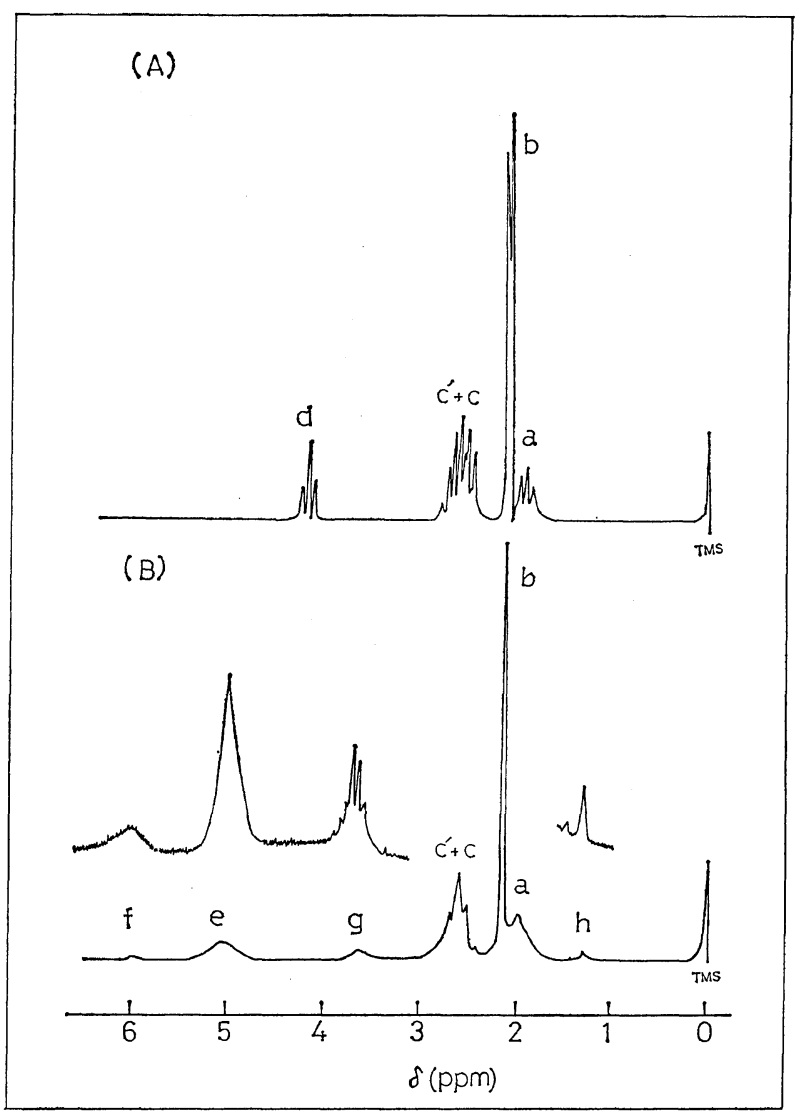

Figure 1. IR spectra of the dimeric ester (a), the linear oligomer (b), and the polymer (THF soluble part, c) of MTPA.

spectrum of the dimeric ester contains a triplet due to the methylene proton $\mathrm{O}=\mathrm{COCH}_{2}-$ group, while in the spectrum of the oligomer the same signal was not observed. In addition, the latter contains peaks $e, f, g$, and $h$, which cannot be found in the former. A broad peak at $5.1 \mathrm{ppm}$ (peak e) correspouds to the proton of the unit $+\mathrm{OCH}+\mathrm{O}-$ The weak $\mathrm{f}$ (5.80$6.25 \mathrm{ppm}$ ) can be assigned to the methine proton which is adjacent to the carboxyl group, $\mathrm{CH}_{3}-$

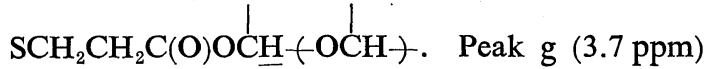
can be assigned to the oxymethylene proton of the unit $-\mathrm{CHOCH}_{2}-$ by analogy with the chemical shift of an ether. The methylene proton of $-\mathrm{CH}_{2} \mathrm{O}-$ group appears usually at a higher field than that of $-\mathrm{CH}_{2} \mathrm{OC}=\mathrm{O}$. The weak singlet singnal at $1.28 \mathrm{ppm}$ (peak h) can be assigned to the methyl proton of the $t$-butoxy group, which may indicate the transfer of the $t$-butoxy group in $\mathrm{Et}_{2} \mathrm{AlOBu}^{t}$ to form a chain end. The molecular weight of the oligomer can be determined from the intensity ratio of the main peaks according to the following equation: $\mathrm{MW}=104(2+n), n=(14+R) /(R-7)$, wherein $R=$ (total area of peaks a, b, c, and $\left.c^{\prime}\right) /($ area of peak e).

The observed values were in agreement with the data obtained by the vapor-pressure osmometry.

\section{Tracer Experiments}

The Polymerization with Radioactive Catalysts at $-78^{\circ} \mathrm{C}$. It is well known that application of the tracer technique using a radioactive initiator or terminator generally gives direct information on the polymerization mechanism and on polymer end groups. However, because the 


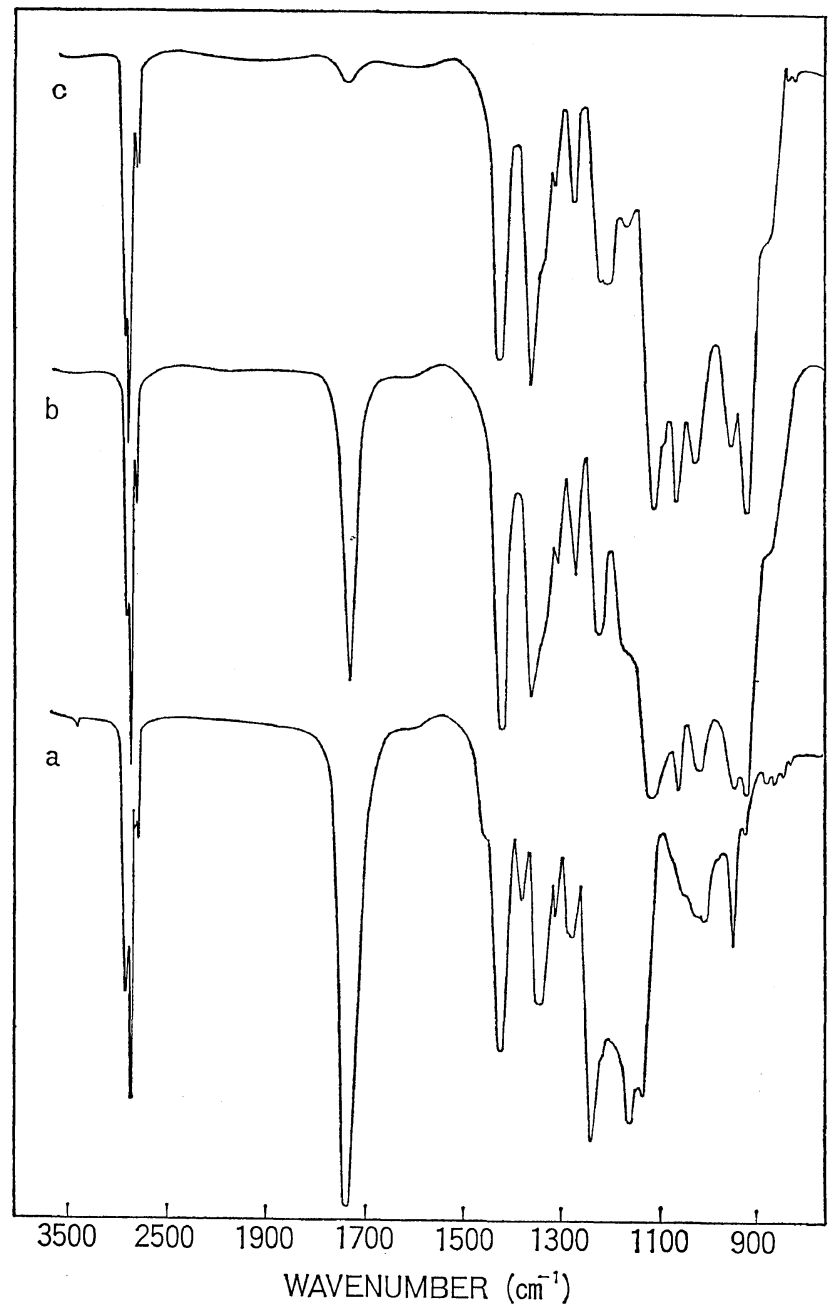

Figure 2. NMR spectra of the dimeric ester (A) and the linear oligomer (B) of MTPA.

polymers of the usual higher aldehydes including acetaldehyde are unstable and almost insoluble in all organic solvents, the tracer technique is unavailable. On the other hand, for the polymerization of sulfur-containing aldehyde the method is effective.

Table IV shows the results of the polymerization of ETBA by using the reaction product of $\mathrm{AlEt}_{3}$ with $\mathrm{Bu}^{\mathrm{t}} \mathrm{OH}$ (molar ratio, $1: 0.5-1: 3$ ) as catalyst. In all cases, radioactive polymers were obtained. In the course of such a migration of the $t$-butoxy group in initiator into the polymer, two processes, that is, an initiation step and a termination step, may be anticipated. The former may easily be realized by the follow- ing equation, on the basis of a coordinated anionic mechanism: ${ }^{2,6}$

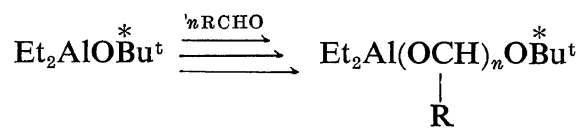

Comparable values for both the degree of polymerization and the specific radioactivity (Table IV, B) of the resultant polymer were obtained regardless of the kind of alkoxides used. It is seen that $1-3 \%$ of total initiator used migrates into the polymer, as shown in Table IV. In the case of the polymerizatian using $1 \mathrm{~mol} \%$ of initiator, the degree of polymerization of the produced polymer was increased, while the in- 
Table IV. Polymerization of ETBA with $\mathrm{AlEt}_{3}-\stackrel{-\mathrm{*}}{-\mathrm{BuOH}}$ Catalystsa

\begin{tabular}{|c|c|c|c|c|c|}
\hline \multicolumn{2}{|c|}{ Catalyst } & \multicolumn{3}{|c|}{ Polymer } & \multirow{2}{*}{$\begin{array}{l}\text { Catalyst efficiency } \\
\qquad(E)^{\mathrm{d}}\end{array}$} \\
\hline$t \stackrel{*}{\mathrm{BuO}} / \mathrm{Al}$ & $\underset{\mathrm{dps}^{\mathrm{b}}}{\text { Radioactivity, }}$ & $\begin{array}{l}\text { Yield }(A), \\
\mathrm{g}(\%)\end{array}$ & $\bar{P}_{n}^{\mathrm{c}}$ & $\begin{array}{c}\text { Radioactivity }(B) \\
\mathrm{dps} / \mathrm{g}\end{array}$ & \\
\hline 0.5 & $2 \times 10^{4}$ & $1.92(64)$ & 794 & $48 \pm 1$ & \\
\hline 1 & $4 \times 10^{4}$ & $2.37(79)$ & 518 & $317 \pm 3$ & 1.9 \\
\hline 2 & $8 \times 10^{4}$ & $2.31(77)$ & 655 & $301 \pm 3$ & $1.7^{e}$ \\
\hline 3 & $1.2 \times 10^{5}$ & $2.19(73)$ & 546 & $441 \pm 4$ & $2.4^{\mathrm{e}}$ \\
\hline $1^{\mathrm{f}}$ & $1.33 \times 10^{4}$ & $2.67(81)$ & 1606 & $108 \pm 2$ & $2.2 \mathrm{~g}$ \\
\hline
\end{tabular}

a ETBA, $3 \mathrm{~g}$; toluene, $6 \mathrm{ml}$; catalyst concn $3 \mathrm{~mol} \%$; time, $24 \mathrm{hr}$; temp, $-78^{\circ} \mathrm{C}$.

b Specific radioactivity in $t$ - $\stackrel{*}{\mathrm{BuOH}} 5.86 \times 10^{7} \mathrm{dps} / \mathrm{mol}$.

c Calculated from $[\eta]=5.15 \times 10^{-5} M^{0.95}$.

d $E=\left(A \cdot B / 4 \cdot 10^{4}\right) \times 100$.

- Calculated by assuming that only one alkoxy group in the catalyst immigrates to initiate polymerization.

I Catalyst concn, $1 \mathrm{~mol} \%$.

g $E=\left(A \cdot B / 1.33 \cdot 10^{4}\right) \times 100$.

Table V. Polymerization of MTPA by $\mathrm{Et}_{2} \mathrm{AlOBu}^{t}$ a

\begin{tabular}{llccc}
\hline $\begin{array}{c}\text { Temp } \\
{ }^{\circ} \mathrm{C}\end{array}$ & Product & $\begin{array}{r}\text { Yield }(A), \\
\mathrm{g}\end{array}$ & $\begin{array}{r}\text { Radioactivity }(B), \\
\mathrm{dps} / \mathrm{g}\end{array}$ & $\begin{array}{c}\text { Catalyst efficiency } \\
(E)\end{array}$ \\
\hline-25 & Ester & 4.5 & 1267 & 21.4 \\
& Oligomer & 0.5 & 3517 & 6.6 \\
-30 & Ester $^{\mathrm{b}}$ & 2.9 & 1250 & 13.6 \\
& Oligomer $^{\mathrm{c}}$ & 0.4 & 3367 & 5.1 \\
-35 & Ester & 2.7 & 950 & 9.6 \\
& Oligomer & 0.4 & 3483 & 5.2
\end{tabular}

a MTPA, $0.05 \mathrm{~mol} \%(5.2 \mathrm{~g})$; catalyst, $0.0005 \mathrm{~mol}$; catalyst radioactivity, $2.66 \times 10^{4} \mathrm{dps}$; bulk polymerization; time, $24 \mathrm{hr}$.

b Contains $0.5 \mathrm{~mol} \%$ of radioactive ester.

c Contains $3.5 \mathrm{~mol} \%$ of radioactive oligomer.

d $E=\left(A \cdot B / 2.66 \times 10^{4}\right) \times 100$.

itiator efficiency was similar. The radioactivity of the polymer by $\mathrm{AlEt}_{3}-\stackrel{*}{\mathrm{Bu}} \mathrm{u}^{\mathrm{O}} \mathrm{OH}(1: 0.5)$ system was relatively low as compared with that by $\mathrm{AlEt}_{3}-{ }_{\mathrm{Bu}}^{\mathrm{B}} \mathrm{OH}(1: 1)$. The former system is anticipated to contain an equivalent amount of $\mathrm{AlEt}_{3}$ and $\mathrm{Et}_{2} \mathrm{AlOBu}^{\mathrm{t}}$. Therefore, this fact seems to indicate the presence of competitive initiations by two species, $\mathrm{Et}_{2} \mathrm{AlOBu}^{\mathrm{t}}$ and the $\mathrm{Et}_{2^{-}}$ $\mathrm{AlOR}^{\prime}$ formed by a Grignard-type reaction of ETBA with $\mathrm{AlEt}_{3}$. The by-product TP was also radioactive, which indicates the coexistence of a small amount of $t$-butyl- $\beta$-ethylthiobutyrate with the dimeric ester, $\beta$-ethylthiobutyl- $\beta$ - ethylthiobutyrate.

Polymerization by Radioactive Catalyst at $-25--35^{\circ} \mathrm{C}$. The results of the polymerization of MTPA using $\mathrm{Et}_{2} \mathrm{AlOBu}^{\mathrm{t}}$ as initiator are shown in Table V. In all cases, both TP and the linear oligomer were radioactive. The fact accorded well with the results obtained in the polymerization at $-78^{\circ} \mathrm{C}$. The radioactivity in the TP fraction can be attributed to $t$-butyl- $\beta$ methylthiopropionate, which formed in the first step of the Tishchenko reaction. The content of $t$-butyl- $\beta$-methylthiopropionate was calculated to be about $0.5 \%$. The ratio of the oligomer with radioactive end, $t$-butoxy end to the total 
oligomer was estimated to be $3.5 \%$ on the assumption that the mean value of the molecular weight of the linear oligomer was 500 in all. This fact implies that a chain transfer reaction takes place frequently. These observations can be explained in terms of the following mechanism proposed by Furukawa, et al: ${ }^{2}$
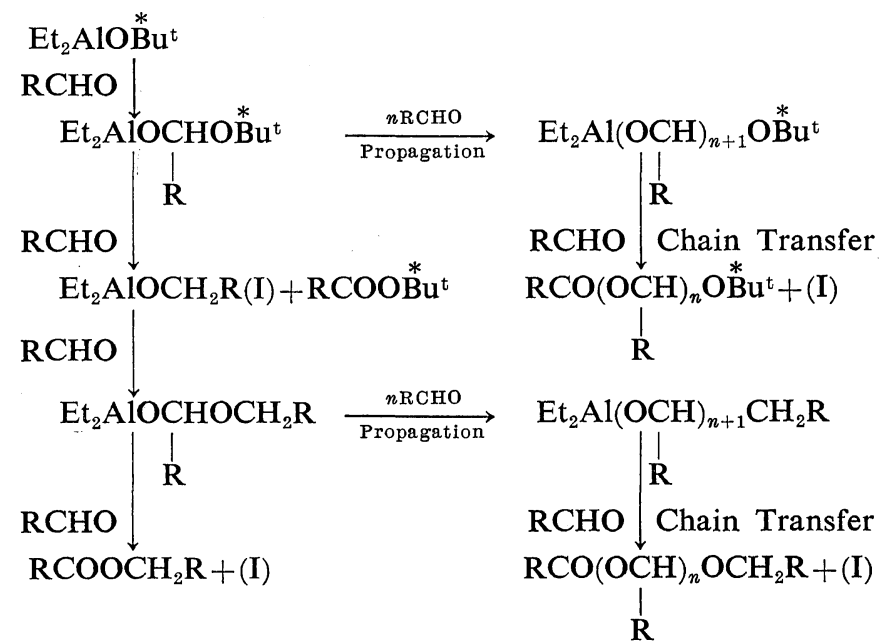

Termination with Radioactive Methanol. A second explanation for the formation of the radioactive polymer at $-78^{\circ} \mathrm{C}$ may be possible by a cationic mechanism, as follows. In this case, the radioactive group immigrates into the polymer at a selftermination step. On the other hand, the termination of the propagating ion pair with $\stackrel{*}{\mathrm{C}} \mathrm{H}_{3} \mathrm{OH}$ forms a radioactive polymer. ${ }^{10}$

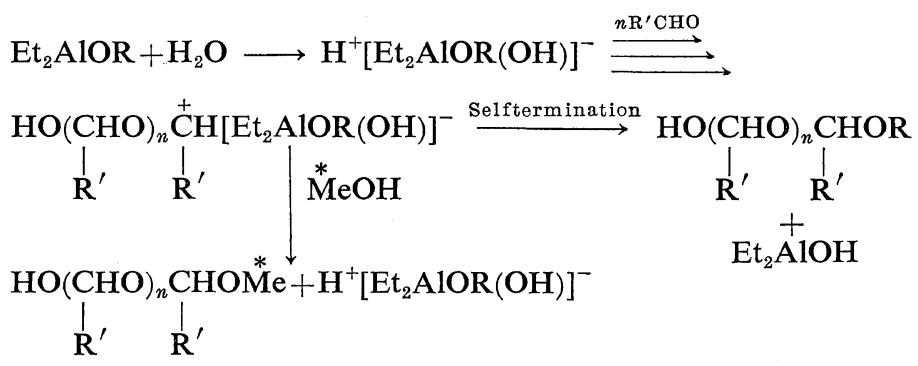

As a preliminary test, the termination with $\stackrel{*}{\mathrm{C}} \mathrm{H}_{3} \mathrm{OH}$ of the cationic polymerization of ETBA by typical Lewis acids was tried. EE-soluble and THF-soluble polymers were purified by acetylation and thereafter repeating the reprecipitation with methanol from THF solution. As given in Table VI, the polymer of both fractions always exhibited radioactivity. This indicates qualitatively that the methoxy group of methanol can be combined chemically to the propagating cationic polymer end. Based on this, the termination with $\stackrel{*}{\mathrm{C}} \mathrm{H}_{3} \mathrm{OH}$ was applied to organoaluminum-induced polymerization in order to examine the presence of cationic species. As shown in Table VII (together with the results of the control experiments), in the polymerization with $\mathrm{AlEt}_{3}$ as well as with $\mathrm{AlEt}_{3}$ $t$-butyl alcohol, the radioactivity in the polymer was negligible.

\section{Additional Discussion}

For the polymerization of acetaldehyde by $\mathrm{AlEt}_{3}$, two types of initiation species, $\mathrm{Et}_{2} \mathrm{AlOAlEt}_{2}$ and $\mathrm{Et}_{2} \mathrm{AlOR}$, have been assumed $;^{2,6,11}$ for the propagation process two 
Table VI. Termination with $\stackrel{*}{\mathrm{C}} \mathrm{H}_{3} \mathrm{OH}$ of polymerization with cationic catalysts ${ }^{\mathrm{a}}$.

\begin{tabular}{|c|c|c|c|c|c|c|}
\hline \multicolumn{2}{|c|}{ Catalyst } & \multicolumn{5}{|c|}{ Polymer } \\
\hline & $\begin{array}{l}\text { Concn, } \\
\text { mol\% }\end{array}$ & Fraction & $\underset{\%}{\text { Yield, }}$ & $\begin{array}{l}{[\eta]} \\
\mathrm{d} l / \mathrm{g}\end{array}$ & $\overline{\boldsymbol{P}}_{n}$ & $\begin{array}{c}\text { Radioactivity, } \\
\text { dps/g }\end{array}$ \\
\hline $\mathrm{SnCl}_{4}$ & 2 & EE-soluble & 11 & 0.1 & & $1571 \pm 15$ \\
\hline $\mathrm{SnCl}_{4}$ & 1 & " & 24 & 0.24 & & $885 \pm 9$ \\
\hline \multirow[t]{2}{*}{$\mathrm{AlBr}_{3}$} & 1 & " & 21 & 0.55 & 133 & $362 \pm 3$ \\
\hline & & THF-soluble & 59 & 2.2 & 573 & $87 \pm 1$ \\
\hline
\end{tabular}

Table VII. Termination with $\stackrel{*}{\mathrm{C}} \mathrm{H}_{3} \mathrm{OH}$ of polymerization using organoaluminum catalysts $^{\mathrm{a}}$

\begin{tabular}{|c|c|c|c|c|c|c|}
\hline \multicolumn{3}{|c|}{ Catalyst } & \multirow{2}{*}{$\begin{array}{c}\text { Polymerization } \\
\text { timee, } \\
\mathrm{hr}\end{array}$} & \multicolumn{3}{|c|}{ Polymer } \\
\hline & & $\begin{array}{l}\text { Concn, } \\
\text { mol } \%\end{array}$ & & $\begin{array}{c}\text { Yield, } \\
\%\end{array}$ & $\bar{P}_{n}$ & $\begin{array}{c}\text { Radioactivity, } \\
\text { dps/g }\end{array}$ \\
\hline \multicolumn{2}{|c|}{$\mathrm{AlEt}_{3}-t-\mathrm{BuOH}(2: 1)$} & 3 & 0.5 & 23 & 1390 & $2 \pm 1$ \\
\hline " & $(1: 1)$ & 3 & 1 & 14 & 573 & $2 \pm 1$ \\
\hline " & $(1: 1)$ & 3 & 1.5 & 12 & 491 & $3 \pm 1$ \\
\hline " & $(1: 3)$ & 3 & 1.5 & 11 & 518 & $3 \pm 1$ \\
\hline \multicolumn{2}{|l|}{$\mathrm{AlEt}_{3}$} & 1 & 1 & 8 & 1047 & $3 \pm 1$ \\
\hline \multirow{2}{*}{\multicolumn{2}{|c|}{ Control }} & 1.5 & 2 & 78 & 600 & $1 \pm 1$ \\
\hline & & & & & & $3-6 \pm 1$ \\
\hline
\end{tabular}

a ETBA, $3 \mathrm{~g}$; toluene, $6 \mathrm{ml}$; temp, $-78^{\circ} \mathrm{C}$; terminator, ${ }_{\mathrm{C}}^{*} \mathrm{H}_{3} \mathrm{OH} 5 \mathrm{ml}\left(2.67 \times 10^{6} \mathrm{dps}\right.$, $2.16 \times 10^{7} \mathrm{dps} / \mathrm{mol}$ ) was added at $-40^{\circ} \mathrm{C}$.

alternative concepts, coordinate anionic ${ }^{2,6}$ and coordinate cationic ${ }^{12}$ mechanisms, have already been suggested. It was pointed out that in the acetaldehyde polymerization by organoaluminum a trace amount of water is indispensable for the initiation, from the fact that the monomer dried thoroughly by using synthetic zeolite F-9 can no longer be polymerized. ${ }^{13}$ On the other hand, it has been observed that the polymerization of higher aldehydes such as butyraldehyde by $\mathrm{AlEt}_{3}$ is insensitive to water content in the polymerization system. ${ }^{14}$ In the polymerization of ETBA by $\mathrm{Et}_{2} \mathrm{AlOBu}^{\mathrm{t}}$, the system dried with synthetic zeolite F-9 rather rapidly polymerized in comparison with the untreated system to give a comparable polymer yield, which was unaffected by the catalyst concentration in the range of $0.5-3$ mol $\%$. In addition, as previously described, the by-product in the polymerization by organoaluminum differs from the one in the cationic polymerization. From these observations, it may be assumed that a coordinated anionic mechanism is preferable. This assumption seems to be further supported by the fact that the polymerization was not inhibited by the addition of a small amount of pyridine. Formation of a linear oligomer having ester end groups, as well as formation of radioactive linear oligomer and radioactive polymer in the polymerization by $\mathrm{Et}_{2} \mathrm{AlOB} \mathrm{Bu}^{t}$, is consistent in this concept.

The predominant chain transfer which resulted in the linear oligomer having an ester group and an alkoxy group as the chain end, seems to be attributable to the presence of a thioether group in the neighborhood of the aluminum. The present fact is in agreement with that obtained in the polymerization of acetaldehyde by $\mathrm{AlEt}_{3}$-sulfur-containing alcohol $(1: 3)$ catalyst systems, in which a stable oligomer having acetyl end group was formed. ${ }^{15}$ The possibility of a cationic mechanism was further examined. 
In experiments which used $\stackrel{*}{\mathrm{C}} \mathrm{H}_{3} \mathrm{OH}$ as a terminator, the radioactivity $(0.01-0.03 \mathrm{~mol} \%$ to catalyst) detected in the polymer was the same order as that in control experiments. Further, these values were not affected by the polymerization conditions, such as the drying of monomer solution with synthetic zeolite F-9 prior to polymerization, or the polymerization in the presence of a small amount of pyridine (5-10 mol\% to catalyst). From these facts, it is most unlikely that the polymerization proceeds by a cationic mechanism in the case of the polymerization of sulfur-containing aldehydes even in the presence of a trace amount of water.

Acknowledgements. The authors wish to thank Mr. J. Iyoda for useful suggestions about the NMR analysis.

\section{REFERENCES}

1. N. Yamamoto and I. Yamashita, Polymer J., 3, 704 (1972).

2. J. Furukawa, T. Saegusa, H. Fujii, A. Kawasaki, H. Imai, and Y. Fujii, Makromol. Chem., 37, 149 (1960).
3. N. Yamamoto and I. Yamashita, Polymer J., 3, 698 (1972).

4. J. Furukawa, T. Saegusa, and H. Fujii, $J$. Polym. Sci., Part C, 4, 281 (1963).

5. O. Vog1, Chem Ind., (London), 748 (1961).

6. H. Fujii, I. Tsukuma, T. Saegusa, and J. Furukawa, Makromol. Chem., 82, 32 (1965).

7. T. Saegusa, K. Hirota, E. Hirasawa, and H. Fujii, Bull. Chem., Soc. Japan, 40, 967 (1967).

8. T. Saegusa, T. Ueshima, S. Kauchi, and S. Kitagawa J. Org. Chem., 33, 3657 (1968).

9. T. Saegusa, T. Ueshima, and S. Kitagawa, Bull. Chem. Soc. Japan, 42, 248 (1969); 40, 1960 (1967).

10. P. H. Plesch, "Chemistry of Cationic Polymerization," Ed., Pergamon Press, Oxford, 1963, p 687.

11. S. Ishida, J. Polym. Sci., 62, 1 (1962).

12. H. Tani, Advances in Polymer Science, 11, 57 (1973).

13. H. Tani et al., Abstracts SPSJ, 17th symposium on Macromolecules, Matsuyama, October, 1968.

14. A. Tanaka et al., Kobunshi Kagaku (Chem. High Polymers) 22, 321 (1965).

15. N. Yamamoto and I. Yamashita, Nippon Kagaku Kaishi (J. Chem. Soc. Japan, Chem. Ind. Chem.), (2425) 1974. 